Nigerian Journal of Technology (NIJOTECH)

Vol. 34 No. 3, July 2015, pp. $523-529$

Copyright@ Faculty of Engineering,

University of Nigeria, Nsukka, ISSN: 0331-8443

www.nijotech.com

http://dx.doi.org/10.4314/njtv34i3.14

\title{
IONOSPHERIC EFFECTS ON GPS SIGNAL IN LOW-LATITUDE REGION: A CASE STUDY REVIEW OF SOUTH EAST ASIA AND AFRICA
}

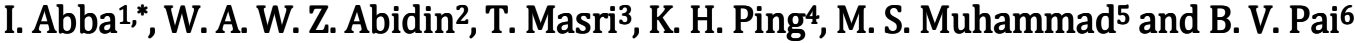 \\ 1, Department of Electrical / Electronic Technology, Kano State Polytechnic, Kano, Kano State. Nigeria. \\ 2, 3,4,5,6 DEPT OF ELECTRONIC ENGINEERING, UNIVERSITI MALAYSIA SARAWAK 94300 KotA SAMARAHAN, MALAYSIA

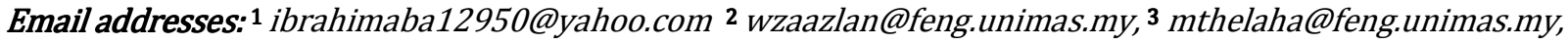 \\ 4 hpkismet@feng.unimas.my, 5 msaufee@feng.unimas.my, 6 13010149@siswa.unimas.my
}

\begin{abstract}
The ionosphere is a significant source of errors affecting L-Band (1-2 GHz) signal propagation using Global Position System (GPS). The propagated GPS signals that passes through the Earth's atmosphere where affected by ionosphere and troposphere irregularities and caused the signal propagation delay. However, the velocity of signals that propagate within the atmosphere deviates from vacuum line of sight (LOS), while the refractivity of ionosphere and troposphere influence the signal propagation delay causing atmospheric effects due to high electrons density. Both affect the signal in different ways due to their particular refractive properties. The review focuses of some of the previous research studies conducted on empirical modeling of the ionospheric effect in low latitude region. The tabulated findings of such models presented in this article.
\end{abstract}

Keywords: Low-latitude, ionospheric effect, GPS, TEC, SNR

\section{INTRODUCTION}

The launching of 24 NAVISTAR satellites was completed by U.S Air force on 26th June 1993 and the network of these satellites is called Global Positioning System (GPS). These NAVSTAR satellites were designed by Rockwell International. Initially, the operation started in 8th December 1993, but full functioning commenced on 27th April 1995[1]. The orbits inclined at about $55^{\circ}$ to the equatorial plane and is located approximately $20,183 \mathrm{~km}$ above the earth's surface[1], [2]. The network of these satellites provides continuous 24 hours coverage to all parts of the globe. GPS has been under development, operated, and maintained by the U. S. Department of Defense (DoD). Because of its uniqueness and its potential applications, particularly related to mobile users, the NAVSTAR GPS deserves particular attention especially the ionospheric nature that cause signal fading. The signals could be intersperse with interfering signals. However, GPS link is more likely to be susceptible to limiting conditions. Such as rain attenuation, multipath fading, shadowing effect, Doppler shift, interference and ionosphere scintillation [4]-[6]. In this research review, only ionospheric effect for open space signals will be considered.
GPS provides special coded satellite signals that will be processed by GPS receivers and enabling them to compute position, speed and time. The Precise Point Positioning (PPP) for GPS tasks using four mobile satellite signals to compute positions in three dimensions in the receiver clock. GPS provides accurate locations, time information at a particular precise position at all different weather around the world [7][9].

Using the GPS dual frequencies receiver system to eliminate ionospheric delays provides a useful tool for measuring the ionospheric total electron content (TEC). Atmosphere becomes an important medium for the GPS signal communication path, but ionospheric effect degrades the signal as a result of fading effect and presence of much electrons contents. These electrons densities will cause the scintillation effect [10]-[12].

This literature studies will focus on the past and present ionospheric studies conducted in the lowlatitude regions, given much emphasis on some part of South-East Asia and Africa regions.

\section{IONOSPHERIC EFFECT}

GPS signals that transmit from the satellite at a distance of 20,183 km, passes through a vacuum until they reach 
the last few percent of their journey. The signals encounter the bulk of free electrons around $350 \mathrm{~km}$, and it is these particles that affect the speed at which the signal propagates [6], [13]. The signals travel at a velocity of light through space, but they are slowed slightly by varying degrees in direction as they pass through the ionosphere [7], [14]. Regular and unusual solar activity can produce variations in the effect of the ionosphere on GPS signals results in errors at atmospheric height of about $100 \mathrm{~km}$. Figure 1 shows the ionosphere region according to the height. The receiving signals will cause the receiver to have ranging errors such as ephemeris data, satellite clock, pseudorange and multipath.

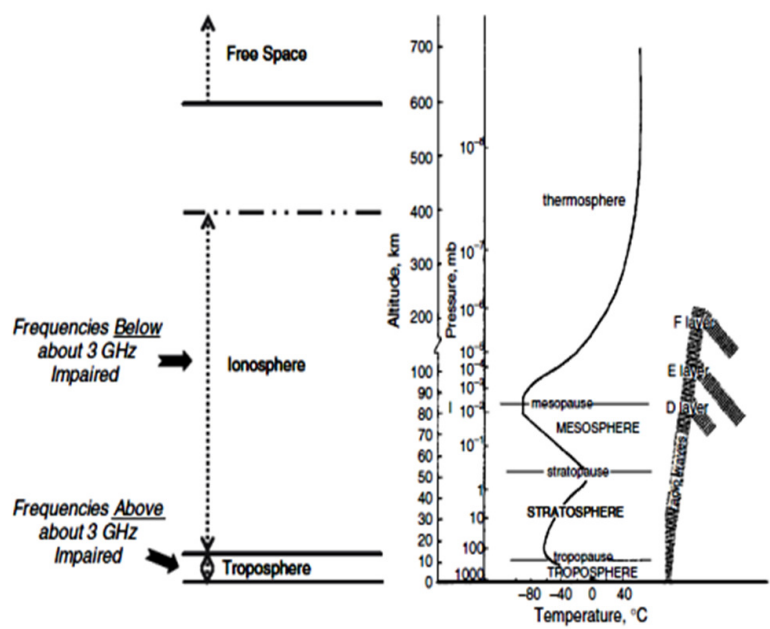

(a)

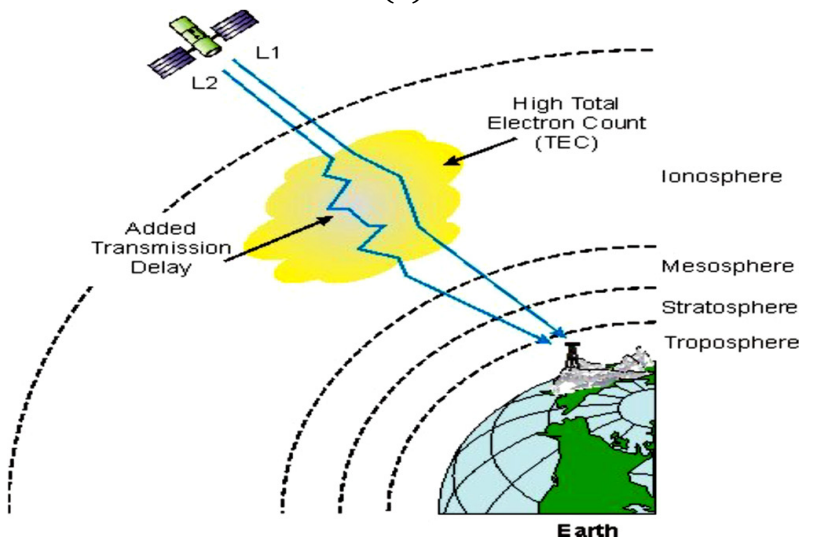

(b)

Figure 1 (a) The Vertical height of Ionosphere F, E and $D$ region and (b) Signal affected at ionosphere region [15].

Radio waves propagation passing through the ionospheric region was described by Appleton-Hartee formula[16], [17] of ionospheric refractive index and group delay. The delays can be summarized as:
- Propagation that causes signals delay in the presence of ionosphere results in increased errors in position and navigation Scintillation effects caused losses of signal due to small-scale irregularities in the ionosphere.

The ionospheric errors equations GPS approach can be written as

$$
\mu=1-a \frac{N}{2}
$$

and $\alpha=40.3 m^{2} s^{-2} N$; denotes the free electrons density per cubic meter ${ }_{\mu}{ }_{i}$, is the ionospheric group delat with respect to propagation in vacuumand $f$ is the radiowave frequency in $\mathrm{GHz}$. Note that, effect of ionospheric refraction index is inversely proportional to the square frequency that causes a delay in time $\Delta t$ that is:

$\Delta t_{i}=\frac{1}{c} \int_{T}^{R}(\mu i-1) d l=\frac{1}{c} * \frac{a}{2} \int_{T}^{R} N d l$

The quantity Ndlis the Total Electron Content (TEC), in electrons per square meter, integrated along the signal path between transmitter $(T)$ and receiver $(R)$, Cis the speed of light. In carrier phase measurements, the effect causes a phase advance leading to an underestimated (shorter) range

Some previous measurements were done by other researchers utilizing the Faraday's rotation using linearly polarized equation signal delay and the circularly polarized GPS signal [17][18]. Therefore the frequency delay can be rewrites as follows:

$$
\Delta t_{\text {phase }} f \frac{40.3 T E C}{2} \leq 0
$$

whereby the time delay can be expressed using phase change multiplied by the frequency in radian/second.

$$
\Delta \phi 2 \pi f \tau=2 \pi \frac{k}{f}=4 \pi^{2} \frac{k}{w}
$$

The ionospheric effect observables equation is given by Pseudo-range,

$\psi=p+d_{I g r}+d_{I}^{\text {len }}=P+\frac{P}{2}+\frac{q}{3}+\frac{u}{4}+d_{I}^{\text {ler }}$

Phase is

$$
f \quad f \quad f
$$

$\phi=P-d_{I}^{\text {len }}=P-\frac{P}{2}+\frac{q}{3}+\frac{u}{4}+d_{I}^{\text {ler }}$

$$
f \quad f \quad f
$$

where $f$ is the signal frequencies for GPS L1 and L2 $(f=1.2276 \mathrm{GHz}$ and $f=1.57542 \mathrm{GHz}), \quad d_{\text {Igr }}$ is the group delay, $d_{I}^{l e n}$ is excess path length of the signal, $u$ is the electron concentration at slant height, $q$ is the 
instrumental biases and $P$ is the distance on geometric between satellite and the receiver[19].

\subsection{Ionospheric Parameter}

Tabulated results in Table 1 obtained from the research conducted at different locations for different years provides summary of ionospheric disturbances affecting these areas. The effects were investigated using Ionos TEC equipment having dual frequency receiver at a vertical height of $400 \mathrm{~km}$ in 2005 by Rashim Wahi, utilized TEC data and frequency rate of $0.5 \mathrm{~Hz}$ [20]. A research conducted on the ionospheric effect on a Malaysian atmosphere by varying the TEC according to the height using the IONosphere map Exchange (IONEX) data and show the total electrons content affecting the radio signals [21]. Ya'acob in model prediction of ionospheric effect utilizes the Jones 3-D ray tracing and Nequick International software[22]. The model can be used to get differential ionospheric delay in sub-centimetre accuracy. Therefore, the model was suitable only for short baseline prediction and single frequency users.

The studies of ionospheric disturbances were carried out in 2010 using commercial handheld GPS receiver by Abba et al., analyzing the Signal to Noise Ratio (SNR) with respect to elevation angles and azimuth angles of received propagations GPS signal. Ionospheric effect observed on some Pseudorandom noise code (PRN)s orbiting the sky of Samarahan as shown in Figure 2 for the PRN 15 indicating the fading of the received SNR signal. Similar study of ionospheric effects on GPS propagation signal was also conducted using logarithmic and polynomial regression model by [5] in Samarahan Malaysia, whereby the model of cumulative frequency function (CDF) shows, some satellites experienced signal fading on 3rd February and 12th March 2010 as shown in Figure 3. Using single frequency handheld GPS receiver data, the analysis shows that PRN 9[23] and PRN 14 were affected by ionospheric disturbances (Figure 3). The ionospheric irregularities at equatorial region occur more than $40 \%$ of the year at 20.00 LT to 02.00 local time (LT) by Li et al., 2009 [24][25].

In 2012, an analysis of ionospheric effect was done by [26] in Hong Kong, evaluating the signal intensity (SI) from the narrowband power (NBP) and wide band power (WBP) using the parameters of phase and amplitude scintillation. The ionospheric disturbances affect more than eight satellites whereby PRN 15 has the highest impact of the amplitude scintillation effect. Table 2 summarizes the affected PRNs Mobile Satellites (MS) signal. Simultaneous observations were conducted on the ionospheric anomalies by [27] in low latitude African region, and some MS was affected which includes PRN 6, PRN 15 and PRN 24. These cause massive fading for the signals. Ionospheric anomalies studies conducted at Asia low latitude region of by [28] analyzed 2004 GPS data taken from the reference stations and found out that MS for PRN 1 S4 index was high at that particular local time

Table 1: Some models error on ionospheic studies conducted at low latitude regions of South East Asia and Africa

\begin{tabular}{|c|c|c|c|c|}
\hline $\begin{array}{l}\text { Year } \\
\text { carried out }\end{array}$ & Region & Techniques / Model applied & Parameters & References \\
\hline 2005 & Low latitude Malaysia & $\begin{array}{l}\text { Investigate IONOS TEC, using } \\
\text { dual frequency receiver at } \\
\text { vertical height of } 400 \mathrm{~km}\end{array}$ & $\begin{array}{l}\text { TEC data, Frequency rate } \\
(0.5 \mathrm{~Hz})\end{array}$ & {$[20]$} \\
\hline 2008 & Low latitude Malaysia & $\begin{array}{l}\text { TEC variation according to } \\
\text { height using IONEX data }\end{array}$ & TEC data, Heights and IONEX & {$[21]$} \\
\hline 2009 & Low latitude Malaysia & $\begin{array}{l}\text { Jones } 3-\mathrm{D} \text { ray tracing method } \\
\text { and Nequick international }\end{array}$ & $\begin{array}{l}\text { TEC data, Elevation angle } \\
\text { and height }\end{array}$ & {$[22]$} \\
\hline 2010 & Low latitude Malaysia & $\begin{array}{l}\text { Observation of TEC using a } \\
\text { mapping function, leveling } \\
\text { process and Matlab software }\end{array}$ & $\begin{array}{l}\text { TEC data, F layer, Receiver } \\
\text { Independent Exchange } \\
\text { Format(RINEX) and pseudo- } \\
\text { range }\end{array}$ & [29] \\
\hline 2010 & Low latitude Malaysia & $\begin{array}{l}\text { Single frequency commercial } \\
\text { receiver used to stored GPS } \\
\text { propagation data }\end{array}$ & $\begin{array}{l}\text { Azimuth }(\varphi) \text {, Elevation }(\theta) \text {, } \\
\text { Signal to noise ratio }(\operatorname{SNR}) \text {, } \\
\text { propagation time }(\mathrm{t})\end{array}$ & {$[2]$} \\
\hline 2011 & Low latitude Malaysia & $\begin{array}{l}\text { Evaluation of handheld GPS } \\
\text { receiver data using } \\
\text { mathematical model } \\
\text { approach }\end{array}$ & $\begin{array}{l}\text { Elevation angles, Azimuth, } \\
\text { SNR and time }\end{array}$ & {$[5]$} \\
\hline
\end{tabular}




\begin{tabular}{|c|c|c|c|c|}
\hline $\begin{array}{l}\text { Year } \\
\text { carried out }\end{array}$ & Region & Techniques / Model applied & Parameters & References \\
\hline 2012 & $\begin{array}{l}\text { Low latitude Hong } \\
\text { Kong }\end{array}$ & $\begin{array}{l}\text { Signal intensity SI can be } \\
\text { calculated from the narrow } \\
\text { band power (NBP) and wide } \\
\text { band power (WBP) }\end{array}$ & $\begin{array}{l}\text { Phase scintillation }\left(\sigma_{\phi}\right) \text { and } \\
\text { amplitude scintillation }\left(S_{4}\right)\end{array}$ & {$[26]$} \\
\hline 2012 & Low latitude Malaysia & $\begin{array}{l}\text { Using Handheld GPS receiver } \\
\text { to evaluate signal strength }\end{array}$ & $\begin{array}{l}\text { Azimuth }\left({ }^{\varphi}\right) \text {, Elevation }(\theta) \text {, } \\
\text { Signal to noise ratio(SNR), } \\
\text { propagation time }(\mathrm{t})\end{array}$ & {$[23]$} \\
\hline 2012 & $\begin{array}{l}\text { Low latitude Bhopal } \\
\text { India }\end{array}$ & Rate of TEC (ROT) & $\begin{array}{l}\text { TEC, GPS data Geomagnetic } \\
\text { field }\end{array}$ & {$[30]$} \\
\hline 2012 & $\begin{array}{l}\text { Low latitude Africa } \\
\text { (Cape Verde, Lagos } \\
\text { and Kampal) }\end{array}$ & $\begin{array}{l}\text { Rayleigh-Taylor, Algorithms } \\
\text { by Gopi Seemala (GPS-TEC } \\
\text { program) }\end{array}$ & $\begin{array}{l}S_{4} \text { index, TEC data, } F_{10.7} \text { solar } \\
\text { flux }\end{array}$ & {$[31]$} \\
\hline 2013 & $\begin{array}{l}\text { Low latitude } \\
\text { Africa(Librevile, } \\
\text { Mbarara and Malindi) }\end{array}$ & $\begin{array}{l}\text { Linear least square, ROT and } \\
\text { GPS-TEC program by Gopi }\end{array}$ & $\begin{array}{l}\text { TEC data SYM-H index, } \\
\text { receiver phase and code } \\
\text { values }\end{array}$ & {$[27]$} \\
\hline 2013 & Low latitude India & $\begin{array}{l}\text { Ephemeris threat Models } \\
\text { using message field range test }\end{array}$ & $\begin{array}{l}\text { TEC data, scintillation index, } \\
\text { elevation angle, azimuth } \\
\text { angle and Carrier to Noise( } \\
\mathrm{C} / \mathrm{N}_{\mathrm{o}} \text { ) }\end{array}$ & {$[28]$} \\
\hline
\end{tabular}

Table 2: Affected mobile satellite signal by ionospheric disturbances

\begin{tabular}{lll}
\hline Affected (MS) & Max S $_{4}$ & Max $\sigma_{\varphi}$ (radians) \\
\hline PRN 08 & 0.87 & 1.14 \\
PRN 12 & 0.97 & 0.79 \\
PRN 14 & 0.68 & 0.71 \\
PRN 15 & 1.08 & 0.38 \\
PRN 17 & 0.63 & 0.60 \\
PRN 18 & 0.69 & 0.09 \\
PRN 21 & 0.63 & 0.13 \\
PRN 25 & 0.79 & 0.27 \\
PRN 27 & 0.62 & 1.03 \\
PRN 29 & 0.78 & 0.26 \\
\hline
\end{tabular}

\section{$2.2 \mathrm{Tec}$}

GPS messages propagate through the ionosphere;the propagation velocity and direction of the GPS signal are changed in proportion due to the varying electron density along the line of sight (LOS) between the receiver and the satellite [1,32-34]. The concentrated electrons effect the radio signal, by the time the signal reaches the receiver is equivalent to the integrated TEC, the quantity of electrons in a column stretching from the receiver to the satellite and the crosssectional area of one square metre. This indeed affects the GPS range parameters; therefore a delay is attached to the code measurements and an increase to the phase observables. To achieve accurate and precise positioning from GPS system, these delays must be taken into account [35]. An in-depth studies of
TEC variation for the ionosphere and a realistic forecast for the occurrence of 1 - $2 \mathrm{GHz}$ frequency scintillations in the equatorial and low latitude $\mathrm{F}$ region using the GPS TEC data $[36,37]$.

The ionospheric effect on satellite navigation range measurements is highly variable. During a low solar activity period, the uncorrected ionosphere would typically cause vertical (zenith) field measurement delays from $1 \mathrm{~m}$ at night to 5-10 $\mathrm{m}$ during the day. However, during peak periods of solar activity, the delay can vary from $1 \mathrm{~m}$ at night to $100 \mathrm{~m}$ during the early afternoon [25]. Even more important from a navigational perspective is that there can be vast spatial slopes in the ionospheric effect on scale measurements. Depending on the class of the receiver used the gradient could cause meaningful positional errors. Ngwira [27] proposed a model of ionospheric effect due to the magnetic storm in the low-latitude region of some part of Africa where four GPS reference stations were used, and the presence of TEC fluctuation was computed given by higher values of ROT [29], [38] corresponds to the period of electron density depletion on. The computed data for the 13th to 15 th September 2004 and gave the results as shown in Figure 4 for PRN 15 and PRN 24 in which the value of ROT is severely affected by ionospheric disturbances.

Total electron content prediction was made by Abdullah [29]utilizing the ionospheric data from Malaysia GISTM reference data station. 


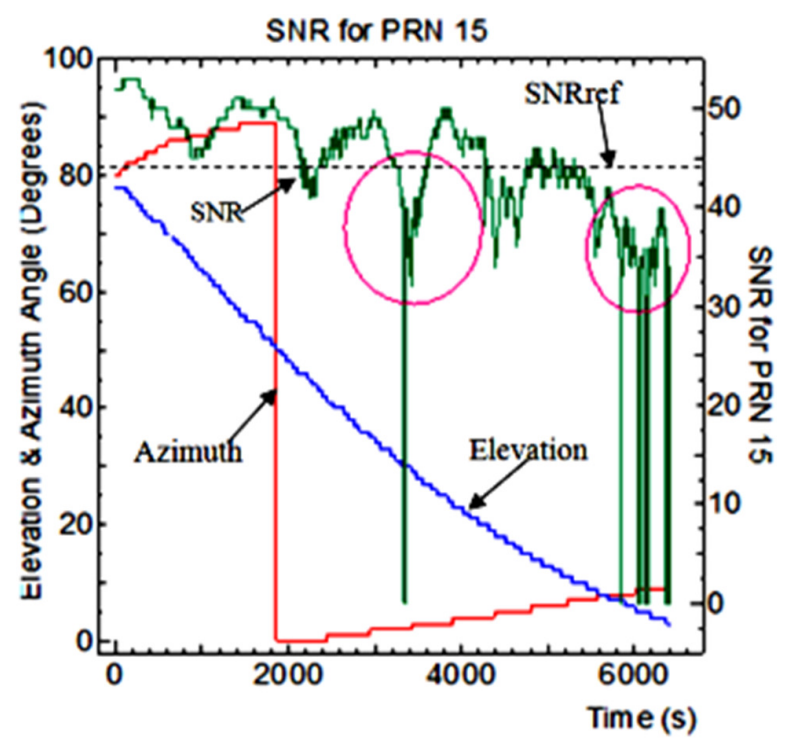

Figure 2: Signal for PRN
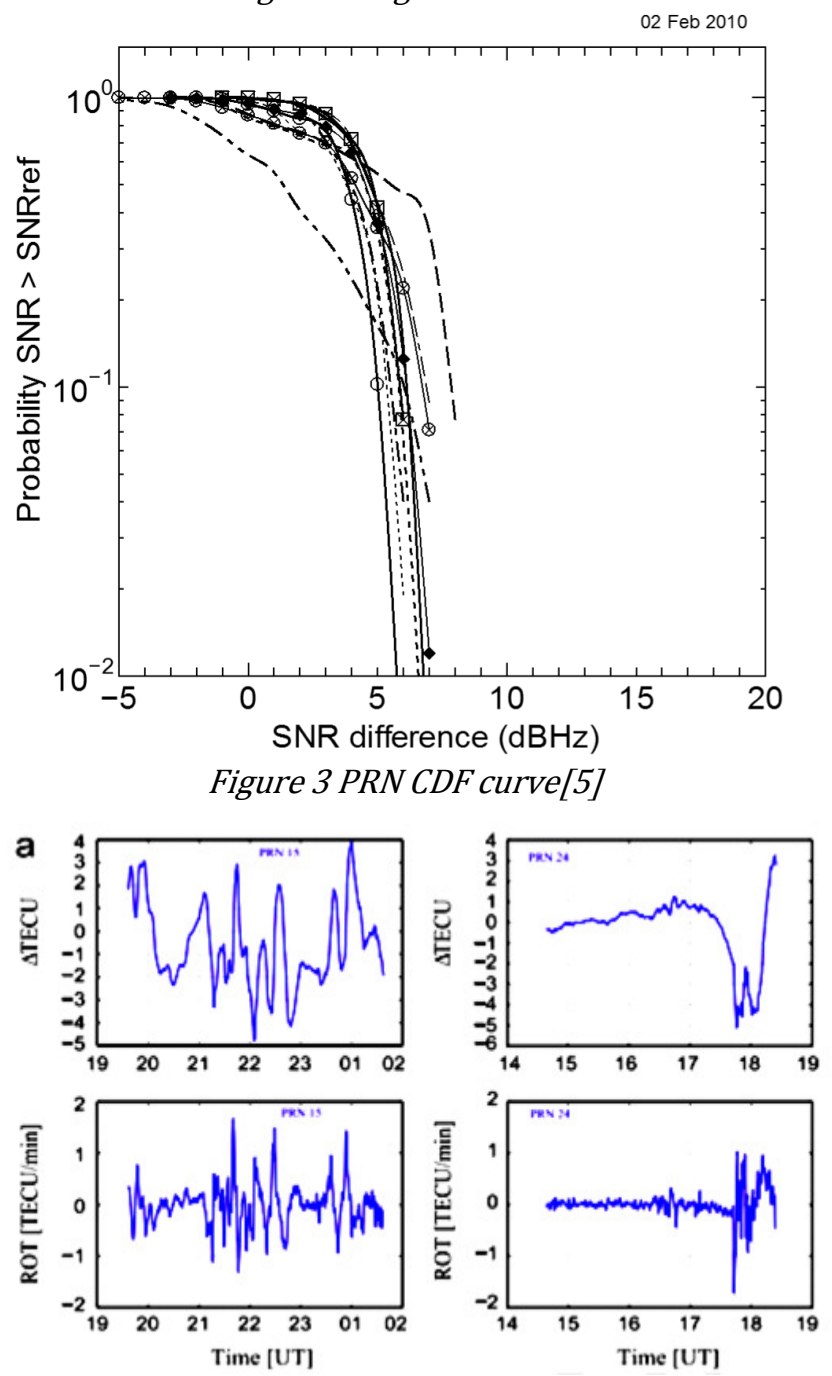

Figure 4: PRN 15 and PRN 24[27]

The ionospheric TEC measurement predicted the inherent fluctuations in pseudo-range and the TEC map shows variation of TEC from morning, noon, and afternoon. PRN 23 satellite signal observed the absolute ionospheric range error obtained due to group delay at two different stations within Malaysia. However, the prediction model[29] is limited only by GPS data available whereas the use of GALILEO and GLONASS data will enhance the accuracy of the prediction of the ionospheric TEC at low latitude region.

\section{CONCLUSION}

Mobile satellite signal performance is affected by several factors such as ionospheric effect, fading due to multipath and shadowing effect. These problems necessitate the need for experimental data in less developed and developing countries such as Asia, Africa and Latin America for the study and analysis of mobile satellite signal performance for communication purposes. Thus, experimental work is necessary to be carried out to investigate the effects and factors such as tree and building-shadowing on the signal strength. The literature studies done cover some, but not all the studies conducted on ionospheric disturbances in the Low-latitude region in South East Asia, as well as Africa. Therefore, GPS technique of ionospheric models allows analysing different effects on the state of ionospheric disturbances. MS users particularly the GPS users should be cautious of the times and regions that have ionospheric disturbances such as active amplitude fading and phase scintillation effects. Furthermore, the available prediction models or services should be applied when a particular planning observation is made.

\section{ACKNOWLEDGMENT}

The authors thank Universiti Malaysia, Sarawak for funding this research.

\section{REFERENCES}

[1] E. D. K. and C. J. Hegarty, Understanding GPS Principles and Applications, Second Edi. Boston London: Artech House Inc., 2006, p. 7479.

[2] Abba, W. a. W. Z. Abidin, V. P. Bong, a. K. Othman, and K. H. Ping, "Open space experimental work for L-band mobile satellite (MS) using a simple and low cost data acquisition system," Int. Conf. Comput. Commun. Eng., no. May, pp. 1-5, May 2010.

[3] S. S. R. Ahamed, "Technological Strategy of Using Global Positioning System: An Analysis," Int. J. Eng. Sci. Technol., vol. 1, no. 1, pp. 8-16, 2009. 
[4] V. P. Bong, W. a. W. Z. Abidin, I. Abba, a. K. Othman, H. Zen, and T. Masri, "A simple and cost effective data acquisition system for mobile satellite experimental work under tree-shadowed and building-shadowed," Int. Conf. Comput. Commun. Eng., no. May, pp. 1-5, May 2010.

[5] B. V. Pai, W. A. W. Z. Abidin, H. Zen, T. Masri, and M. Abdullah, "Open Space Mathematical Model for the Mobile Satellite L-Band Signal in Sarawak using Global Positioning System Technology," in Proceeding of the 2011 IEEE International Conference on Space Science and Communication (IconSpace) 12-13 July 2011., 2011, no. July, pp. 12-13.

[6] K. F. M. T. Wan A. W. Z. Abidin, "Novel Approach to Determine the Effects of MS Environment using the Portable GPS Receiver with Built-in Antenna," Am. J. Appl. Sci., vol. 5, no. 8, pp. 1079-1082, 2008.

[7] G. S. Kumar, G. S. B. Rao, and M. N. V. S. S. Kumar, “GPS Signal Short-Term Propagation Characteristics Modeling in Urban Areas for Precise Navigation Applications," Positioning, vol. 04, no. 02, pp. 192-199, 2013.

[8] K.-Y. Lee, J.-Y. Kim, K. Putti, D. H. Bennett, D. Cassady, and I. Hertz-Picciotto, "Use of Portable Global Positioning System (GPS) Devices in Exposure Analysis for Time-location Measurement," Korean J. Environ. Heal. Sci., vol. 35, no. 6, pp. 461-467, Dec. 2009.

[9] V. Schwieger, "Using Handheld GPS Receivers for Precise Positioning Using Handheld GPS Receivers for Precise Positioning," in 2nd FIG Regional Conference, 2003, pp. 1-16.

[10] K. Davies and E. K. Smith, "Ionospheric effects on satellite land mobile systems," IEEE Antennas Propag. Mag., vol. 44, no. 6, pp. 24-31, Dec. 2002.

[11] M. T. A. H. Muella, E. R. de Paula, I. J. Kantor, I. S. Batista, J. H. . Sobral, M. A. Abdu, P. M. Kintner, K. M. Groves, and P. F. Smorigo, "GPS L-band scintillations and ionospheric irregularity zonal drifts inferred at equatorial and low-latitude regions," J. Atmos. SolarTerrestrial Phys., vol. 70, no. 10, pp. 1261-1272, Jul. 2008.

[12] G. V. Naveen, D. S. R. I. Ranga, B. V. A. N. Lakshmi, and B. S. Sravan, "Preliminary Ionospheric Scintillation Analysis over Low Latitude GPS Station," Int. J. Electron. Commun. Instrum. Eng., vol. 3, no. 1, pp. 1518, 2013.

[13] J. Goldhirsh and W. J. Vogel, Handbook of Propagation Effects for Vehicular and Personal Mobile Satellite Systems Overview of Experimental and Modeling Results, vol. 021, no. December. Texas, 1998.

[14] B. R. Elbert, The Satellite Communication Applications Handbook, Second Edi. London: Artech House, 2004, pp. 7-14.

[15] J. Louis J. Ippolito, Communications Atmospheric Effects, Satellite Link Design. Washington: A John Wiley and Sons, Ltd, 2008, pp. 89-82.
[16] R. Athieno, "Using co-located radars and instruments to analyse ionospheric events over South Africa," Rhodes University, 2011.

[17] M. M. Hoque and N. Jakowski, "Ionospheric Propagation Effects on GNSS Signals and New Correction Approaches," in Global Navigation Satellite Systems - Signal, Theory and Applications, Germany, 2000, pp. 381-394.

[18] E. J. Petrie, M. Hernández-Pajares, P. Spalla, P. Moore, and M. a. King, "A Review of Higher Order Ionospheric Refraction Effects on Dual Frequency GPS," Surv. Geophys., vol. 32, no. 3, pp. 197-253, Nov. 2010.

[19] S. Gowsuddin and V. B. S. S. I. Dutt, "Ionospheric Parameters Estimation for Accurate GPS Navigation Solution," Int. J. Eng. Adv. Technol., no. 2, pp. 302-305, 2012.

[20] S. D. \& A. K. G. Rashmi Wahi and Space, "Ionospheric total electron content measurement in Malaysian region during high solar activity using GPS receiver," vol. 34, no. December, pp. 399-401, 2005.

[21] N. Ya'acob, M. Abdullah, M. Ismail, S. A. Bahari, and M. K. Ismail, "Ionospheric mapping function for total electron content (TEC) using global positioning system (GPS) data in Malaysia," 2008 IEEE Int. RF Microw. Conf., pp. 386-390, Dec. 2008.

[22] N. Ya'acob, M. Abdullah, U. T. Mara, S. Alam, and S. D. Ehsan, "Model Validation for GPS Total Electron Content ( TEC) using 10th Polynomial Function Technique at an Equatorial Region," in WSEAS TRANSACTIONS on COMPUTERS, 2009, vol. 8, no. 9, pp. 1533-1542.

[23] I. Abba, W. A. W. Z. Abidin, K. H. Ping, and T. Masri, "Measurements and Analysis of Mobile Satellite Signal Performance Using Handheld GPS Receiver," in World Academy of Science, Engineering and Technology 72 2012, 2012, pp. 627-631.

[24] G. Li, B. Ning, L. Liu, W. Wan, and J. Y. Liu, "Effect of magnetic activity on plasma bubbles over equatorial and low-latitude regions in East Asia," Ann. Geophys., vol. 27, pp. 303-312, 2009.

[25] R. Tiwari, S. Bhattacharya, P. K. Purohit, and a. K. Gwal, "Effect of TEC Variation on GPS Precise Point at Low Latitude," Open Atmos. Sci. J., vol. 3, no. 1, pp. 112, Jan. 2009.

[26] R. Xu, Z. Liu, M. Li, Y. Morton, and W. Chen, "An Analysis of Low-Latitude Ionospheric Scintillation and Its Effects on Precise Point Positioning," vol. 11, no. 1, pp. 22-32, 2012.

[27] C. M. Ngwira, G. K. Seemala, and J. Bosco Habarulema, "Simultaneous observations of ionospheric irregularities in the African low-latitude region," J. Atmos. Solar-Terrestrial Phys., vol. 97, pp. 50-57, May 2013.

[28] M. V. Chowdary and M. Anilkumar, "Study of Ionospheric Scintillation at Low Latitude GPS Stations 
And Ephemeris Threat Models," vol. 4, no. April, pp. 913-916, 2013.

[29] M. A. and M. I. Norsuzila Ya'acob, “GPS Total Electron Content ( TEC ) Prediction at Ionosphere Layer over the Equatorial Region," 2010.

[30] S. Chatterjee and P. K. Purohit, "Effect of Ionospheric Perturbation on GPS Observation over Low Latitude Region , Bhopal," 2012.

[31] V. V. Paznukhov, C. S. Carrano, P. H. Doherty, K. M. Groves, R. G. Caton, C. E. Valladares, G. K. Seemala, C. T. Bridgwood, J. Adeniyi, L. L. N. Amaeshi, B. Damtie, F. D’Ujanga Mutonyi, J. O. H. Ndeda, P. Baki, O. K. Obrou, B. Okere, and G. M. Tsidu, "Equatorial plasma bubbles and L-band scintillations in Africa during solar minimum," Ann. Geophys., vol. 30, no. 4, pp. 675-682, Apr. 2012.

[32] B. V. Pai, "Characteristics of mobile satellite L-band signal in mid-latitude region : GPS approach," Indian J. Radio Sp. Phys., vol. 40, no. April, pp. 105-112, 2011.

[33] American Meteorological Societ, "Satellite Navigation \& Space Weather: Understanding the Vulnerability \& Building Resilience," 2011.

[34] L. Lo Presti, B. C. Ferna, and E. Falletti, "Satellite Radiolocalization From GPS to GNSS and Beyond:
Novel Technologies and Applications for Civil Mass Market," Proc. IEEE, vol. 99, no. 11, pp. 1882-1904, 2011.

[35] D. Lee, J. Cho, Y. Suh, J. Hwang, and H. Yun, “A New Window-Based Program for Quality Control of GPS Sensing Data," Remote Sens., vol. 4, no. 12, pp. 31683183, Oct. 2012.

[36] S. Pulinets, "Low-Latitude Atmosphere-Ionosphere Effects Initiated by Strong Earthquakes Preparation Process," Int. J. Geophys., vol. 2012, pp. 1-14, 2012.

[37] R. Sridharan, M. S. Bagiya, and S. Sunda, "A novel method based on GPS TEC to forecast $\mathrm{L}$ band scintillations over the equatorial region through a case study," J. Atmos. Solar-Terrestrial Phys., vol. 80, pp. 230-238, May 2012.

[38] N. Jakowski, Y. Béniguel, G. De Franceschi, M. H. Pajares, K. S. Jacobsen, I. Stanislawska, L. Tomasik, R. Warnant, and G. Wautelet, "Monitoring, tracking and forecasting ionospheric perturbations using GNSS techniques," J. Sp. Weather Sp. Clim., vol. 2, p. A22, Dec. 2012. 